\title{
Assessment of tensile and fatigue behavior of PEEK specimens in a physiologically relevant environment
}

\author{
Mirco Peron, Jan Torgersen, Filippo Berto \\ Department of Mechanical and Industrial Engineering, Norwegian University of Science and Technology (NTNU), Richard \\ Birkelands vei 2b, 7034, Trondheim, Norway. \\ mirco.peron@ntnu.no,jan.torgersen@ntnu.no,filippo.berto@ntnu.no
}

\begin{abstract}
In the last decades the necessity of implant devices is continuously increasing. The researchers have thus focused their attentions on the development of new biocompatible materials, in particular polymers. Among them, polyetheretherketone (PEEK) has gained wide interest in loadbearing applications such as spinal cages due to its yielding behavior and its superior corrosion resistance. Since such applications are characterized by notches and other stress concentrators weakening the implant resistance, a design tool for assessing their tensile and fatigue behavior, in the presence of such discontinuities, is highly claimed. To this aim, tensile and fatigue data available in literature related to neat and differently notched PEEK samples, experimentally tested in a phosphate-buffered saline (PBS) at $37{ }^{\circ} \mathrm{C}$ have been analyzed using the strain energy density (SED) approach. The method is shown to provide accurate results regardless of the different notch geometries, both in terms of tensile and fatigue behavior. Concerning the former, the tensile strength was in fact estimated with an error lower than $\pm 10 \%$, whereas for the latter the SED approach was able to summarize the experimental fatigue data in a single narrow scatter band, independently from the notch geometry.
\end{abstract}

KEYwORDS. PEEK; Tensile; Fatigue; Notch; SED

\section{OPEN ACCESS}

Citation: Peron, M., Torgersen, J., Berto, F., Assessment of tensile and fatigue behavior of PEEK specimens in a physiologically relevant environment, Frattura ed Integrità Strutturale, 47 (2019) 425-436.

Received: 19.11 .2018

Accepted: 02.12.2018

Published: 01.01.2019

Copyright: (C) 2019 This is an open access article under the terms of the CC-BY 4.0, which permits unrestricted use, distribution, and reproduction in any medium, provided the original author and source are credited.

\section{INTRODUCTION}

$\mathrm{I}$ $\mathrm{n}$ recent years, the need of surgical procedures, and consequently the necessity of implant devices, have continuously increased [1]. These implants are generally used for applications that ensure a substantial improvement in patients' quality of life, such as orthopedics, pacemakers, cardiovascular stents, defibrillators, neural prosthetics and drug delivery systems [2-5], but load-bearing implants are characterized by the highest annual growth rate [6] and, posing significant challenges, they have attracted large scale researcher efforts $[4,7,8]$. For example, artificial limbs have to fit 
perfectly to the patient specific site of interest and have to resemble the mechanical properties of the bone to avoid bone resorption due to the stress-shielding phenomenon [9-11]. Moreover, load-bearing implants have to be characterized by sufficient strength since they are intermittently stressed due to weight and activity. For example, prostheses implanted to the lower extremities of the body have to withstand loads several times heavier than body weight [12-14]. In addition, the biologically-attractive implant design of these implants might cause challenging mechanical conditions leading to tensile and fatigue failure. For example, implant porosity is widely reported to enhance osseointegration and it is used to tailor the mechanical properties of the prosthesis to fit the biological site of interest [15]. However, such features lead to stress concentrators that reduces the strength of the components [16]. Moreover, a high surface roughness has been reported to favor the cell adhesion and growth, but at the same time is known to lead to crack initiation [17-20]. These competing requirements are aggravated due to the corrosive environment in the human body, leading to effects such as corrosion fatigue and stress corrosion cracking [21,22]. Sivakumar and Rajeswari reported the failure due to the stress corrosion cracking phenomenon of a 316L stainless steel used for fixing a femoral fracture in a 27 years old man [23]. Yokoyama et al. reported that the failure of a titanium occlusal screw failed after three years of implantation was due to the fatigue crack nucleation at the root of the thread [24]. Moreover, Chao and Lopez reported that corrosion fatigue was responsible of the failure of almost $90 \%$ of Ti-6Al-4V hip prosthesis [25].

In this challenging scenario, a robust and reliable design tool for the prediction of implant tensile and fatigue strength is highly claimed, especially in the presence of stress concentrators. Considering the developments obtained in the engineering field, many researchers and clinicians have tried to assess implant behavior of notched components using linear elastic fracture mechanics (LEFM) theory and, in particular, the notch stress intensity factors (NSIFs) [26]. Concerning the tensile assessment, the NSIF approach predict the failure of a component comparing the NSIF at which the implant is subjected with a reference strength value obtained by testing samples weakened by the same notch geometry. Concerning fatigue, instead, the NSIF approach predicts the fatigue life of notched components comparing the NSIF at which the implant is subjected with a reference fatigue curve determined from samples characterized by the same notch geometry $[27,28]$. However, the reliable applicability of the NSIF approach requires to accurately evaluate the stress field ahead of the geometrical discontinuities, and the time-consuming stress field analyses has thus limited its development. In addition, the NSIF-based criteria are dependent on the geometry and this represent another drawback of this approach. Their unit depends in fact on the notch opening angle: the exponent $\beta$ in their unit $\mathrm{MPa}(\mathrm{m})^{\beta}$ is in fact equal to $1-\lambda_{1}$, where $\lambda_{1}$ is the geometrical dependent Williams' eigenvalue [29]. The geometry dependence implies the necessity of ad hoc experimental data to use the NSIF method, representing thus a complexity in its use. The theory of critical distance (TCD), that represents a set of methodologies, allows to overcome the geometry-dependence limitation. Based on the definition of a material parameter (the critical distance L), the TCD states that failure of notched components subjected either to static or cyclic loadings occurs when the stress averaged over a line (line method, LM) or calculated at a certain distance from the notch root (point method, PM) equals the inherent material strength, $\sigma_{0}$, or the plane specimen fatigue limit, $\Delta \sigma_{0}$, depending on whether tensile or fatigue assessment is considered. The applicability of the TCD to predict the strength of bio-materials has been assessed by Kasiri and Taylor [30]. They applied the LM to predict the fracture behavior of bones, weakened by different holes, and subjected to various loading scenario, but, although the general trend was well predicted, the results underestimated the fracture stress by $20-30 \%$. In fact, it is generally acknowledged by proponents of critical distance methods that the point and line method are limitation of a more accurate approach that average stresses over a certain volume (or area in 2D problems) in the vicinity of the hot-spot. Taylor [31] thus formalized the so-called area method (AM), where the range of the maximum principal stress is averaged over a semicircular area. Although the accuracy of the results increases considering the AM, stress fields ahead of the notch still need to be accurately determined, resulting in high-performance hardware demand. However, although the accuracy of the results increases considering the AM, stress fields ahead of the notch still need to be accurately determined, resulting in high-performance hardware demand. This has been overcome by the strain energy density (SED) approach, according to which failure occurs when the strain energy $\bar{W}$ (or strain energy range $\Delta \bar{W}$ for fatigue loadings) averaged in a control volume of radius, $R_{C}$, ahead of the notch or crack tip reaches its critical value $\mathrm{W}_{C}$ (or $\Delta \mathrm{W}_{C}$ for fatigue), independently from the notch geometry [32-34]. Moreover, the strain energy range can either be obtained analytically, deriving the stress fields ahead of the geometrical discontinuity, or by means of FE analyses with a coarse mesh, being mesh-insensitive $[35,36]$. This tool has been widely reported to accurately predict the tensile and fatigue behavior of different notched materials [37-41] and for real component such as steel rollers [42], and its improvements with respect of the TCD methodologies has been reported in details in [43] for Ti-6Al-4V. In addition, it has recently been utilized to predict the fracture and fatigue behavior of plastics [44-46], including the biocompatible biopolymer polyetheretherketone (PEEK) $[47,48]$. In particular, SED approach has been reported to provide better assessment of the PEEK fatigue life compared to NSIF and TCD approaches [48]. PEEK is considered an emerging material due to its yielding behavior and its superior 
corrosion resistance, also in physiologically relevant environments [4,49-52]. In particular, Williams et al. reported the flexural strength to decrease from $156 \mathrm{MPa}$ to $149 \mathrm{MPa}$ after two months of immersion in simulated body fluid (SBF) at $37{ }^{\circ} \mathrm{C}$ [53]. Due to its outstanding properties, PEEK, besides being studied as a substitute material for metals in gear wheels and food processing [54], has also gained interest in biomedical applications such as spinal cages [55] and dental implants [56,57]. PEEK is in fact characterized by an in vitro bone stimulation capacity comparable to that of CP Ti grade 1 [58] and by an elastic modulus closer to that of human bones compared to that of metals, as reported in [11]. As a consequence, the bone resorption by the stress shielding effect induced by PEEK implant is significantly lower than that induced by titanium and zirconia implants, as assessed by Lee et al. [59]. In addition, they reported un-notched PEEK components to be able to withstand static and cyclic loadings comparable to those deriving by bites in anterior dentitions. Due to the increasing interests in PEEK for biomedical applications, a reliable failure criterion for this material is highly required, especially when weakened by notches, and the authors have herein decided to assess the reliability of the SED approach in predicting the tensile and fatigue behavior of PEEK materials in a physiologically relevant environment. For our reference, we employ the experimental data of Sobieraj et al., that investigated PEEK tensile and fatigue behavior in a physiologically relevant environment in the presence of stress concentrators [60,61]. Their tensile and fatigue data were here analyzed in terms of SED to assess the reliability of the method as a prediction model for biomaterials.

\section{EXPERIMENTAL REFERENCE DATA}

\section{Tensile data}

obieraj et al. [60] examined the stress-strain behavior of neat and notched PEEK specimens under uniaxial loads in a corrosive environment (phosphate-buffered saline solution at $37{ }^{\circ} \mathrm{C}$ ). The specimens were circumferentially grooved round bars with an $8 \mathrm{~mm}$ outer diameter, weakened by three different types of notches. These were circumferentially U-notched geometries with a $6 \mathrm{~mm}$ inner diameter, and moderate $(0.9 \mathrm{~mm})$ or deep $(0.45 \mathrm{~mm})$ notch radii. In addition, a circumferentially razor grooved dog-bone was investigated (Fig. 1).

a)

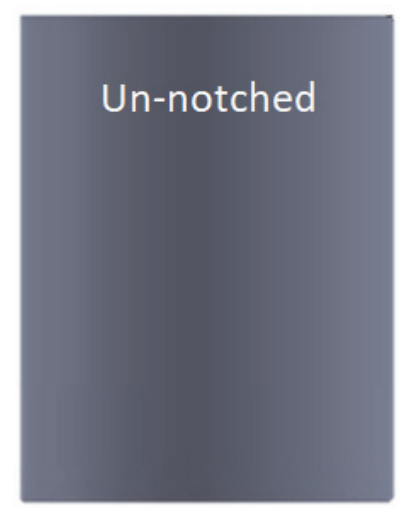

b)

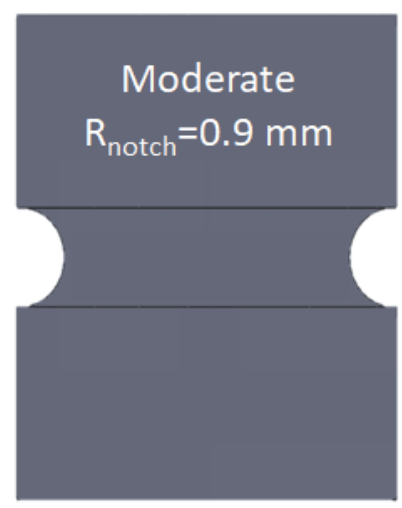

c)

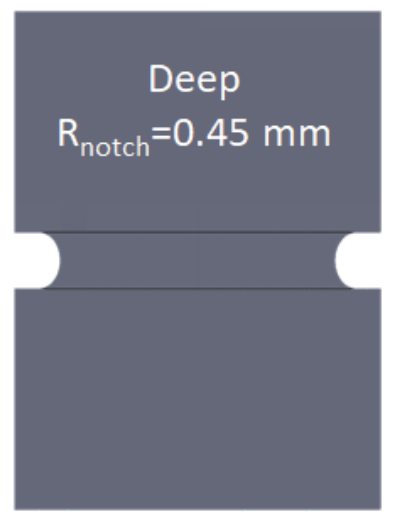

d)

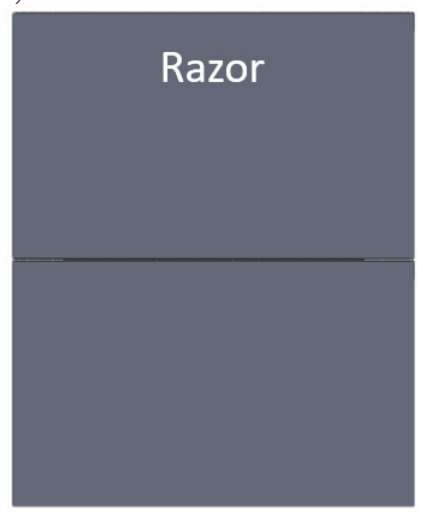

Figure 1: Schematic view of the specimen geometries: a) neat sample; b) U-notched sample with notch radius of 0.9 mm; c) U-notched sample with notch radius of $0.45 \mathrm{~mm}$; d) circumferentially razor grooved dog-bone.

The specimens, made by OPTIMA LT1TM (Invibio, Inc., West Conshohocken, PA, USA), were tested under strain control condition, with two different strain rates at 0.1 and $0.5 \mathrm{~s}^{-1}$. The ultimate tensile strength values, together with the experimental scatter, are listed in Tab. 1. The Young's modulus and the yield stress were reported not to change with the strain rate, confirming the results obtained in Ref. [6], where a strain rate from $0.00001 \mathrm{~s}-1$ to $10 \mathrm{~s}-1$ was reported to negligibly affect these properties.

\section{Fatigue data}

Sobieraj et al. [61] aimed to determine the S-N curve of PEEK in presence of stress concentrators and in a corrosive environment. They preconditioned the specimens for 8 weeks and then carried out fatigue tests in a $37{ }^{\circ} \mathrm{C}$ phosphatebuffered saline (PBS) bath. The samples tested were characterized by the same notched geometries reported in the previous section and shown in Fig. 1. Tension-tension fatigue tests were carried out aiming to assess the fatigue behavior, in a range of number of cycles to failure ranging from 1000 to 100,000 , at a frequency of $2 \mathrm{~Hz}$, with a load ratio equal $\mathrm{R} \leq$ 
0.02. The fatigue data, shown in Fig. 2, were fitted by Sobieraj et al. [61] by means of the S-N Basquin relationship [62] with good results being the mean squared error, $\mathrm{R}^{2}$, higher than 0.90 for all the notched geometry:

$$
\Delta \sigma=A N^{d}
$$

where $\Delta \sigma$ is the stress range, $\mathrm{N}$ is the number of cycles to failure, and $\mathrm{A}$ and $\mathrm{d}$ are constants, listed in Tab. 2.

\begin{tabular}{ccccccccc}
\hline & \multicolumn{2}{c}{ Un-notched } & \multicolumn{2}{c}{ Moderate } & \multicolumn{2}{c}{ Deep } & \multicolumn{2}{c}{ Razor } \\
Strain rate $\left(\mathrm{s}^{-1}\right)$ & 0.1 & 0.5 & 0.1 & 0.5 & 0.1 & 0.5 & 0.1 & 0.5 \\
Max axial true stress & $211 \pm$ & $225 \pm$ & $132 \pm$ & $135 \pm$ & $127 \pm$ & $129 \pm$ & $119 \pm$ & $123 \pm$ \\
$(\mathrm{MPa})$ & 8.2 & 5.4 & 1.1 & 0.4 & 2.3 & 1.4 & 4.9 & 4.3 \\
\hline
\end{tabular}

Table 1: Tensile properties of notched and un-notched polyetheretherketone (PEEK) specimens under different strain rates.

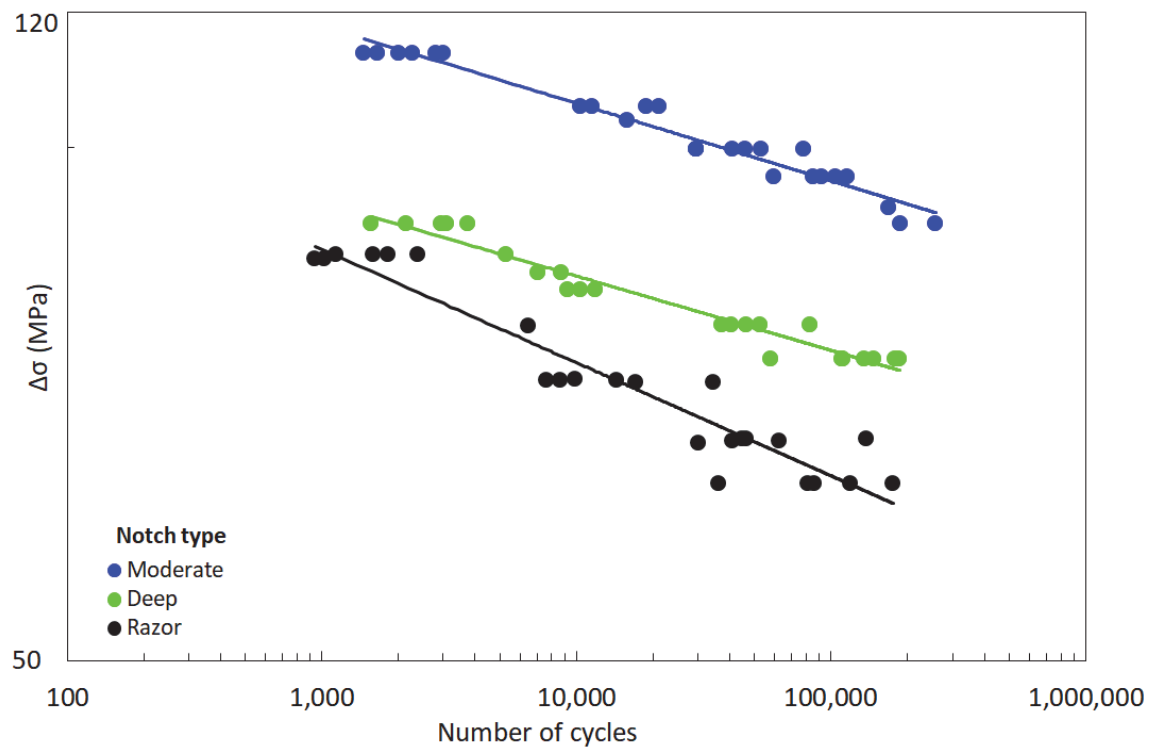

Figure 2: Experimental S-N curves for the three different notched geometries, i.e. moderate (U-notched with a notch radius of 0.9 $\mathrm{mm}$ ), deep (U-notched with a notch radius of $0.45 \mathrm{~mm}$ ) and razor (circumferentially cracked). Modified from Sobieraj et al. [61].

\begin{tabular}{cccc}
\hline Parameter & $\begin{array}{c}\text { Moderate (radius 0.9 } \\
\mathrm{mm})\end{array}$ & $\begin{array}{c}\text { Deep (radius 0.45 } \\
\mathrm{mm})\end{array}$ & Razor \\
$\mathrm{A}(\mathrm{MPa})$ & 152 & 120 & 131 \\
$\mathrm{~d}$ & -0.043 & -0.043 & -0.063 \\
$\mathrm{R}^{2}$ & 0.95 & 0.90 & 0.92 \\
\hline
\end{tabular}

Table 2: S-N Basquin relationship constants. Data taken from Ref. [61].

\section{ANALYTICAL FRAME WORK}

\section{SED approach under static loadings}

7 he SED criterion states that the failure of a component, subjected to tensile loading, occurs when the total strain energy, $\bar{W}$, averaged in a circular control volume of radius $\mathrm{R}_{\mathrm{c}}$ (surrounding a crack or notch tip) reaches its critical value $\mathrm{W}_{c}[63]$. The critical $\mathrm{SED}$ parameters, i.e. the critical radius, $\mathrm{R}_{c}$, and the critical strain energy density, $\mathrm{W}_{c}$, are material dependent"[64], and they can be analytically derived with only few material properties [63]: the ultimate tensile 
strength of the un-notched material, $\sigma_{t}$, the Young's modulus, E, and the fracture toughness, $\mathrm{K}_{\mathrm{IC}}$. In the case of ductile material, the ultimate tensile strength should be replaced with "the maximum normal stress existing at the edge at the moment preceding the cracking" as suggested by Seweryn [65], or the equivalent material concept developed by Torabi should be considered [66]. In agreement with Beltrami [67], the critical value of the total strain energy can be computed by the following equation:

$$
W_{C}=\frac{\sigma_{t}^{2}}{2 E}
$$

In plane problems, the control volume becomes a circular sector or a circle, for $\mathrm{V}$-notches or cracks, respectively (Fig. $3 \mathrm{a}$ and $3 b)$. The critical radius, $R_{c}$, is defined as follow [63]:

$$
R_{C}=\frac{(1+v)(5-8 v)}{4 \pi}\left(\frac{K_{I C}}{\sigma_{t}}\right)^{2}
$$

where $v$ is the Poisson's ratio of the material. For a blunt V-notch or a U-notch (Fig. 3c), the volume is assumed to be of a crescent shape, where $R_{c}$ is the depth measured along the bisector line. The outer radius of the crescent shape is equal to $\mathrm{R}_{\mathrm{c}}+\mathrm{r}_{0}$, with $\mathrm{r}_{0}$ being the distance between the notch tip and the origin of the local coordinate system (Fig. 3c). Such a distance depends on the notch-opening angle, $2 \alpha$, and the notch root radius, $\varrho$, according to the expression:

$$
r_{0}=\varrho \frac{(\pi-2 a)}{(2 \pi-2 a)}
$$

a)

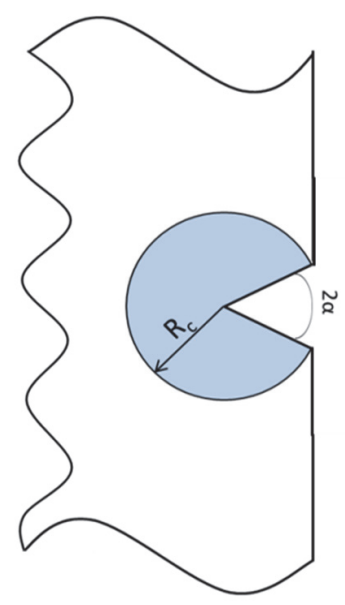

b)

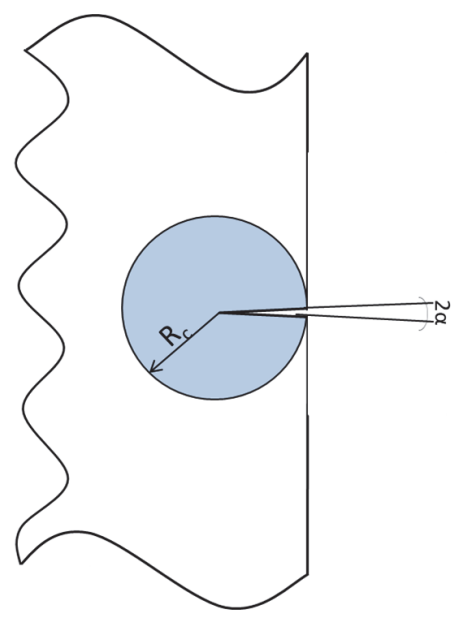

c)

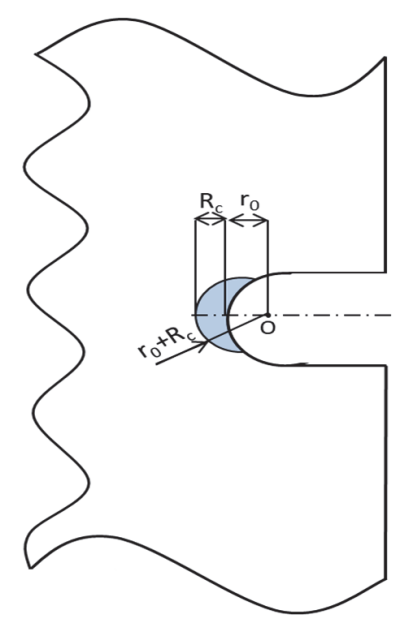

Figure 3: Control volume under mode I loading for: (a) sharp V-notch, (b) crack case and (c) U notch .

However, the fracture toughness is not always available due to the difficulties and time consuming calculations. Yet, an estimate of the critical radius can be obtained as the radius at which the critical SED values $\left(W_{C}\right)$ for two different specimen geometries, are identical [27].

\section{SED approach under fatigue loadings}

Dealing with fatigue loadings, Lazzarin and Zambardi states that failure occurs when the strain energy density range, $\Delta \bar{W}$ , averaged in a control volume of radius $\mathrm{R}_{\mathrm{c}}$ (ahead of the notch or crack tip) reaches its critical value $\Delta \mathrm{W}_{\mathrm{c}}$. In $\mathrm{Ref}$. [63] a simple analytical formulation for the computation of the critical value of the strain energy density range, $\Delta \mathrm{Wc}$, has been proposed:

$$
\Delta W_{C}=\frac{\Delta \sigma_{A}^{2}}{2 E}
$$


where $\Delta \sigma_{\mathrm{A}}$ is the fatigue limit of the material without geometric singularities for fully reversed normal stress. The control volume is defined, as in the previous section, with the only exception that now the formulation of critical radius, $R_{c}$, is defined as follow:

$$
R_{C}=\left(\frac{\sqrt{2 e_{1} \Delta K_{1 A}}}{\Delta \sigma_{A}}\right)^{\frac{1}{1-\lambda_{1}}}
$$

where $\lambda_{1}$ is Williams' eigenvalue for Mode I [29], $\Delta \mathrm{K}_{1 \mathrm{~A}}$ is the amplitude of the Notch Stress Intensity Factors (NSIF) fatigue threshold, and $e_{1}$ is a parameter dependent on the notch opening angle, $2 \alpha$, and on the hypothesis considered (plane strain or plane stress), and on the Poisson's ratio $\nu$ (the reader should referred to Ref. [63] for e 1 formulation). Also, in case of a blunt $\mathrm{V}$-notch or a U-notch, the volume is assumed to be of a crescent shape and defined as for static loadings. As it can be noted from Eqns. (5) and (6), that also in case of dynamic loadings the critical value of the strain energy density, and that of the radius of the control volume, are only dependent on the material [64]. However, in some cases not all the material parameters required to apply SED approach are available. Recently, this shortcoming has been overcome thanks to the possibility provided by some FE codes to easily determined the strain energy within the control volume. Berto et al. [68] analyzed the fatigue behavior of innovative alloys at high temperature and, using Ansys ${ }^{\circledR}$ code, they obtained the critical radius value. This value was obtained varying the control volume until the SED value $(\bar{W})$ for a notched specimen at a certain amount of cycles, matched the critical SED value $\left(\mathrm{W}_{\mathrm{C}}\right)$ obtained for a plain specimen, failed at the same number of cycles (Eq. 5). In this work, neither NSIF fatigue threshold nor fatigue limit of the material without geometric singularities are known, and thus the critical values are obtained using a similar approach to that reported in Ref. [68]. The critical radius has been determined as the value at which the SED values $(\bar{W})$ for two different specimen geometries at the same number of cycles are equal. Moreover, this SED value has been considered as the critical one. A deeper explanation will be provided in the next sections.

a)

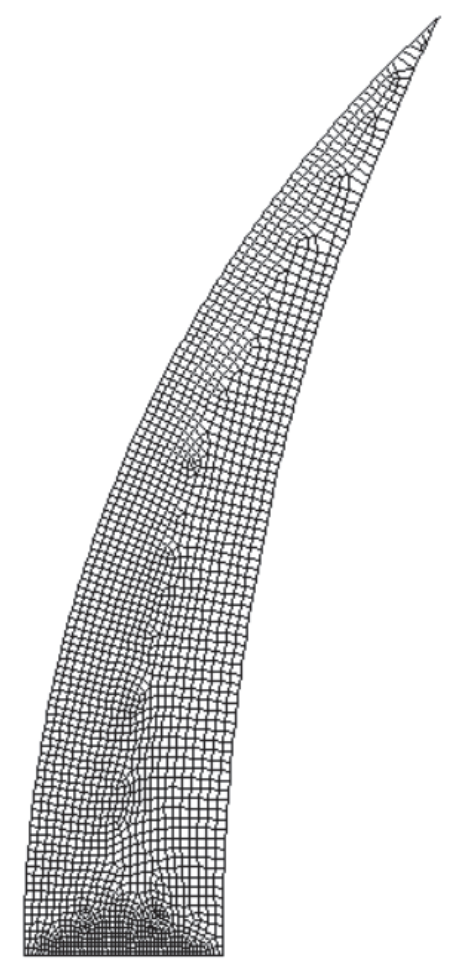

b)

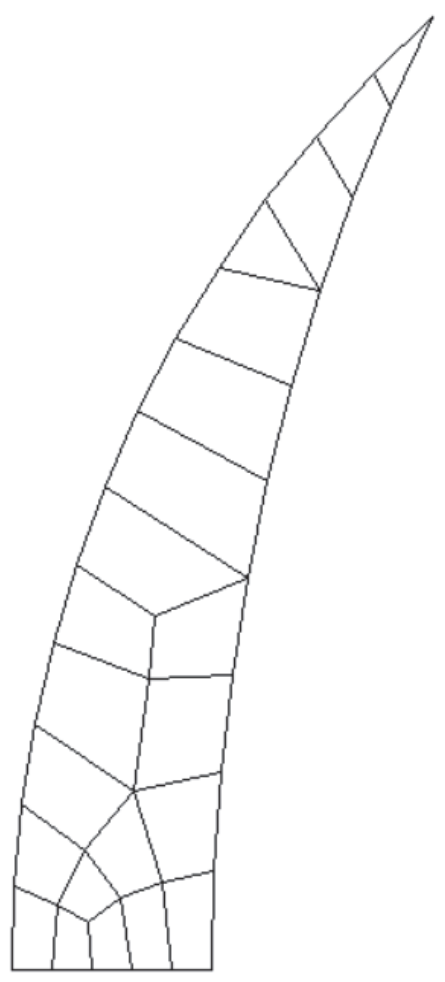

Figure 4: Strain energy density (SED) mesh sensitivity: (a) Number of elements $=2049, \bar{W}=2.8431 \mathrm{MJ} / \mathrm{m}^{3}$; (b) Number of elements $=23, \bar{W}=2.8398 \mathrm{MJ} / \mathrm{m}^{3}$. 


\section{FINITE ELEMENT MODEL}

$\mathrm{I}$ $\mathrm{n}$ order to obtain the SED value $(\bar{W})$, axisymmetric linear elastic $2 \mathrm{D}$ analyses were performed on the notched models. Due to the double symmetry of the geometry only one quarter of the specimens was modeled. The 8-nodes axisymmetric element plane 83 was selected for these analyses. In the FE code, the material was assumed isotropic, with the Young's modulus E $=3500 \mathrm{MPa}$ and the Poisson's ratio $\nu=0.36$, as reported in Ref. [60]. A mesh convergence study was undertaken to ensure that a proper number of elements was used in finite element modelling, with elements size at the crack tip ranging from about $10^{-3} \mathrm{~mm}$ to $10^{-1} \mathrm{~mm}$. The results are independent from the mesh, being the difference only $0.11 \%$ between the SED value for a coarse mesh and that for a fine mesh (Fig. 4), and thus a coarse mesh was adopted for the analyses. The mesh-insensitivity of the SED approach was previously verified also by Berto and Lazzarin [35], for cracked and notched specimens. This represents one of the main advantages of this approach, together with the capability of assessing the tensile behavior of different materials regardless of the geometry.

Fig. 5 illustrates the mesh pattern and the boundary conditions used for finite element analyses. Symmetric boundary conditions were used for vertical and horizontal symmetry lines of the models (as indicated by the triangles in Fig. 5). The top side of the model was able to move along the loading axis to simulate the application of the load.

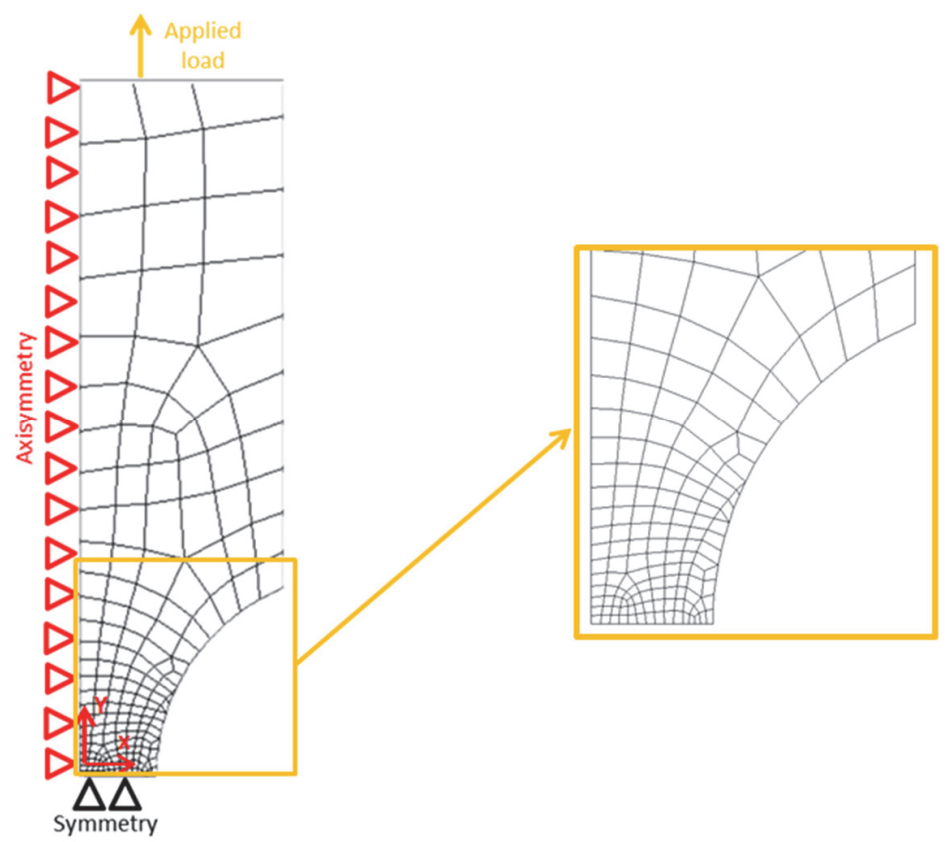

Figure 5: Typical mesh pattern of the finite element model near the notch tip and schematics of boundary conditions.

\section{RESULTS}

\section{Static loading}

obieraj et al. tested un-notched and notched PEEK specimens under different strain rates and in a corrosive - environment, and in this section their results were analyzed in terms of SED. The application of the SED approach requires the computation of both the critical value of the radius, $R_{c}$, of the control volume and that of the strain energy density, $\mathrm{W}_{\mathrm{c}}$. The critical SED value, $\mathrm{W}_{\mathrm{c}}$, can be simply evaluated using Eqn. 2, leading to a critical SED value of 7.278 and $6.38 \mathrm{MJ} / \mathrm{m}^{3}$ under a strain rate of 0.5 and $0.1 \mathrm{~s}^{-1}$, respectively. Concerning the control volume, in reference [60] the fracture toughness has not been reported. Eqn. 3 cannot thus be used, but it is possible to obtain the critical radius, $\mathrm{R}_{\mathrm{C}}$, leveraging on $\mathrm{FE}$ analyses, by changing the radius of the control volume of the specimens with two different control radii and iteratively computing the SED value $(\bar{W})$ ) until a satisfying convergence is reached. In this work, circumferentially razor-grooved dog-bone and U-notched specimen, with a notch root radius of $0.45 \mathrm{~mm}$, have been modelled in Ansys $^{\circledR}$. The simulations have been carried out for different values of $\mathrm{R}_{C}$, ranging from 0.1 to $0.2 \mathrm{~mm}$, with a 
step of $0.01 \mathrm{~mm}$, and the critical radius results to be equal to 0.13 and $0.12 \mathrm{~mm}$ for specimens tested at 0.1 and $0.5 \mathrm{~s}^{-1}$, respectively. The small difference in radius is due to the material's limited strain rates sensitivity below $10 \mathrm{~s}^{-1}$ [69]. As the strain energy density is proportional to the square of the applied stress, the predicted tensile strength of the notched

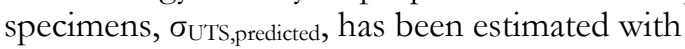

$$
\sigma_{U T S, \text { predicted }}=\sqrt{\frac{W_{c}}{W_{\text {unit_load }}}}
$$

in which $\mathrm{W}_{\mathrm{C}}$ is the critical $\mathrm{SED}$ value (Eqn. (2)) and $\mathrm{W}_{\text {unit_load }}$ is the $\mathrm{SED}$ value determined by means of $\mathrm{FE}$ analyses applying a unit load. The SED prediction of the tensile failure for both the strain rates are reported in Tab. 3 .

\begin{tabular}{ccccc}
\hline Specimen Geometry & Strain Rate $\left(\mathrm{s}^{-1}\right)$ & $\begin{array}{c}\text { Experimental Data } \\
(\mathrm{MPa})\end{array}$ & $\begin{array}{c}\text { SED Prediction } \\
(\mathrm{MPa})\end{array}$ & Deviation $(\%)$ \\
Deep & 0.1 & 127 & 118 & -6.8 \\
\multirow{2}{*}{ Moderate } & 0.5 & 129 & 124 & -4 \\
& 0.1 & 132 & 132 & -0.1 \\
Razor & 0.5 & 135 & 139 & +3.3 \\
& 0.1 & 119 & 118 & -0.8 \\
& 0.5 & 123 & 124 & +0.8
\end{tabular}

Table 3: Prediction of tensile failure of moderate, deep and razor specimens using the SED approach.

For the geometries and test conditions reported in [60], the presented approach provides suitable prediction of tensile failure, where deviations (computed as the relative difference between the experimental and predicted values, and expressed in percentage) are generally lower than $4 \%$, for predictions of moderate and razor grooved merely even below $1 \%$. Impacts of the corrosive test environment were successfully accounted for.

a)

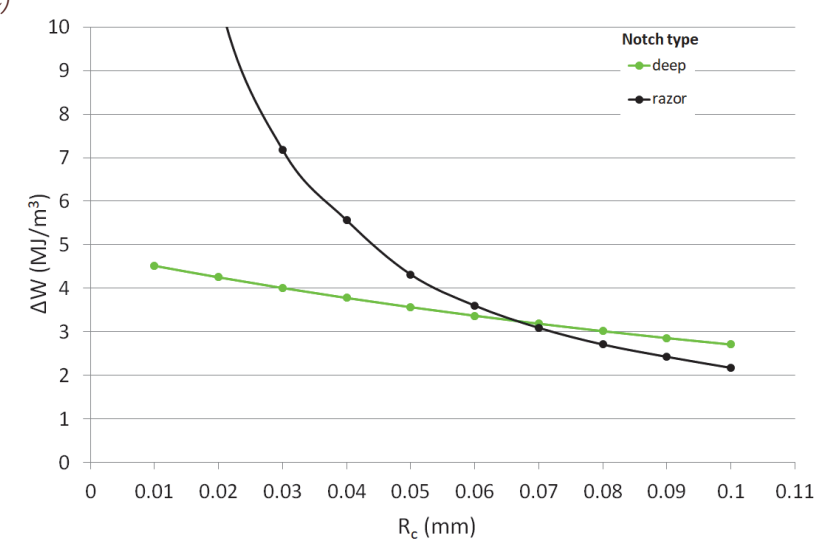

b)

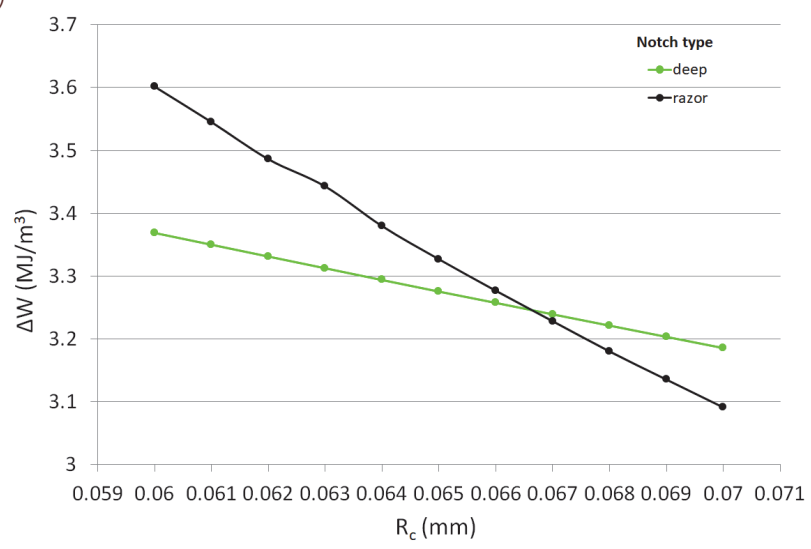

Figure 6: Determination of the SED critical parameters: (a) The value of the critical radius $\mathrm{R}_{\mathrm{C}}$ has been varied with a step of $0.01 \mathrm{~mm}$ and (b) with a finer step of $0.001 \mathrm{~mm}$.

\section{Fatigue loading}

As mentioned earlier, neither the NSIF fatigue threshold nor the fatigue limit of the plain material were available, and thus Eqns. (5) and (6) could not be applied to determine the critical SED parameters. An alternative approach has thus been used using Ansys ${ }^{\circledR}$ : the radius of the control volume has been varied until the SED values for two different specimen geometries, at the same number of cycles, were equal. In particular, circumferentially razor-grooved dog-bone and Unotched specimen, with a notch root radius of $0.45 \mathrm{~mm}$, have been modelled, and the critical radius has been varied from 0.01 to $0.1 \mathrm{~mm}$, with a step of $0.01 \mathrm{~mm}$ (Fig. 6a). Then, in the range between 0.06 and $0.07 \mathrm{~mm}$, where the difference 
between the SED values for the two geometries at 150000 cycles were lower, the simulations have been repeated with a step of $0.001 \mathrm{~mm}$ for the critical radius until a correspondence was found, resulting in $\mathrm{R}_{\mathrm{C}}=0.067 \mathrm{~mm}$ and $\Delta \mathrm{W}_{\mathrm{C}}=3.23$ $\mathrm{MJ} / \mathrm{m}^{3}$ at 150000 cycles (Fig. 6b).

Once the critical radius was determined, the fatigue data shown in Fig. 2 were analyzed in terms of SED range. FE analyses were carried out considering the experimental stress range as the applied load in the simulations, determining the corresponding SED range value, used to obtain the fatigue curve shown in Fig. 7.

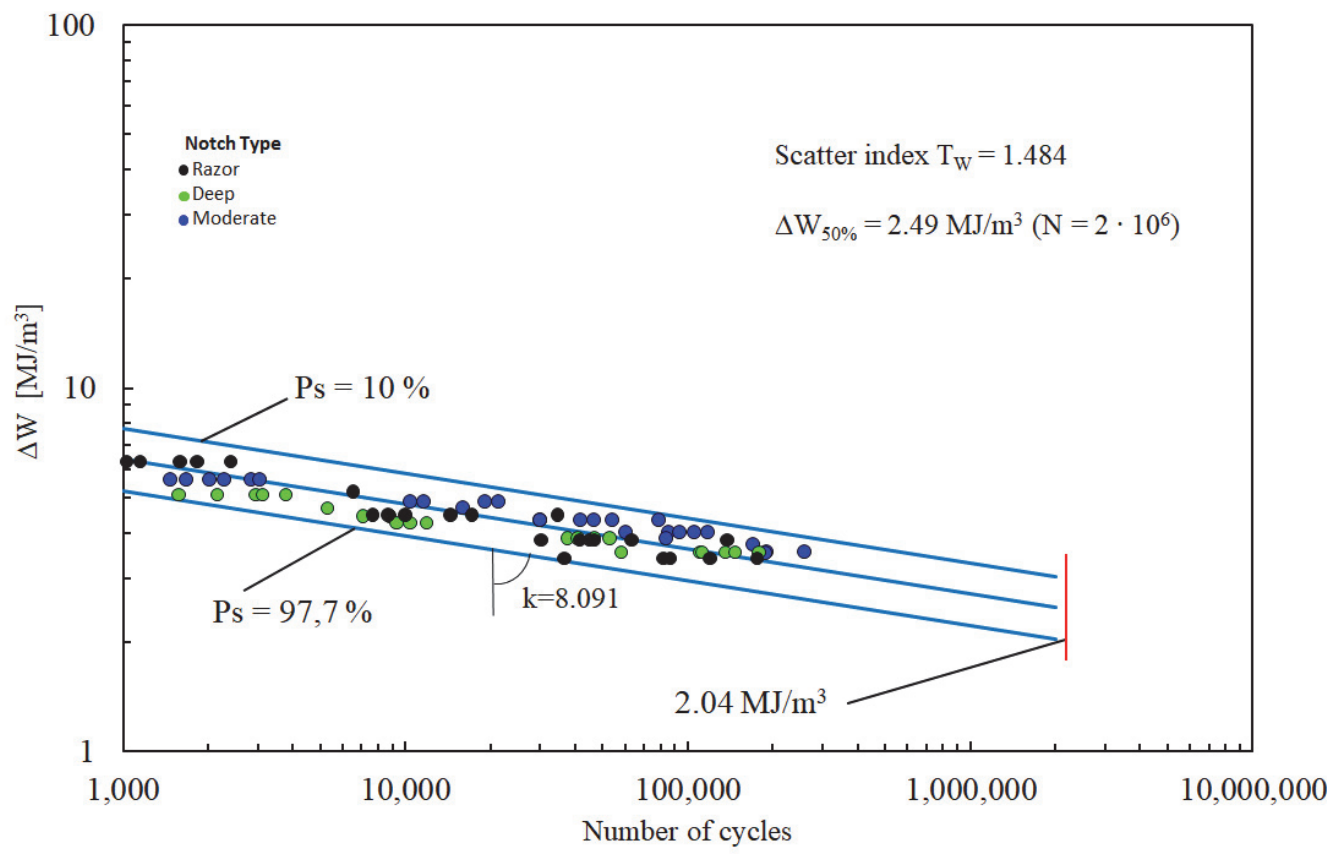

Figure 7: Synthesis of PEEK fatigue data by means of SED approach.

The fatigue results felt within a single narrow scatter band, with an inverse slope $\mathrm{k}=8.091$ and a strain energy density range referred to 2 million loading cycles and to a probability of survival of $50 \%$. In fact, the scatter index $T_{W}$, related to the two curves, with probabilities of survival $\mathrm{P}_{\mathrm{s}}=2.3 \%$ and $97.7 \%$, is equal to 1.484 . $\mathrm{T}_{\mathrm{W}}=1.484$ becomes equal to 1.22 when reconverted to an equivalent local stress range being the SED proportional to the square of the stress $\left(\mathrm{T}_{\sigma}=\sqrt{1.484}\right.$ = 1.22). Comparing Fig. 2 with Fig. 7 it can be noted how the SED approach is able to summarize the fatigue data obtained by using different notch geometries within a single narrow scatter band, whereas the S-N curves, in Fig. 2, show a different behavior for each notch geometry. This represents a milestone in the design of biomedical implants; once a $\Delta \mathrm{W}-\mathrm{N}$ curve had been obtained for any notch geometry, it can be considered as the SED fatigue master curve, which can be used as reference for every kind of notch geometries weakening the components. As it is evident from the just reported procedure, the advantages of SED approach lie on its simplicity and rapidity-to-use that could render it a breakthrough in the design procedures when compared to the methods so far used.

\section{CONCLUSIONS}

he strain energy density (SED) approach has revealed in the past to greatly predict both the tensile and fatigue behavior of metals, weakened by different notch geometries. Herein this approach has been extended to the assessment of the tensile and fatigue behavior of PEEK in corrosive environments. The authors have utilized a previously supplied dataset [60,61], where different notch geometries in a physiologically relevant environment have been tested under static and dynamic loadings. The approach has shown to capture both the strain- and notch-sensitivity of the material. Concerning static loadings, the predictive performance of the tensile strength of PEEK are characterized by a discrepancy to the experimental data in the range of $\pm 10 \%$, the performance range considered acceptable in many studies of a SED database, while, dealing with fatigue loadings, the SED criterion has been shown to summarize fatigue data for different notch geometries within a single narrow scatter band. Compared with the classical NSIF approach, the SED 
criterion overcomes the NSIF approach main limitation of the geometry dependency. In addition, both NSIFs and TCD require high computational efforts, a fine mesh being required ahead of the notch tip, whereas the SED approach has revealed to be mesh-insensitive. This work introduces a milestone in the design of PEEK biomedical devices, providing a simple and rapid method for assessing the tensile and fatigue strength, overcoming the drawbacks of the other methods, and opening the road towards the use of this approach in corrosive environments.

\section{REFERENCES}

[1] Ginebra, M.P., Traykova, T., Planell, J.A. (2006). Calcium phosphate cements as bone drug delivery systems: A review, J. Control. Release, 113(2), pp. 102-110. DOI: 10.1016/j.jconrel.2006.04.007.

[2] Regar, E., Sianos, G., Serruys, P.W. (2001). Stent development and local drug delivery., Br. Med. Bull., 59, pp. $227-48$.

[3] Greatbatch, W., Holmes, C.F. (1991). History of implantable devices, IEEE Eng. Med. Biol. Mag., 10(3), pp. $38-41$. DOI: $10.1109 / 51.84185$.

[4] Long, P.H. (2008). Medical Devices in Orthopedic Applications, Toxicol. Pathol., 36(1), pp. 85-91. DOI: $10.1177 / 0192623307310951$.

[5] Khan, W., Muntimadugu, E., Jaffe, M., Domb, A.J. (2014).Implantable Medical Devices., Springer US, pp. 33-59.

[6] (n.d.). \$21.12 Billion Implantable Biomaterials Market: Global Forecasts to 2023 - Miniaturization of Implant Devices and Increasing Minimally Invasive Surgery. Available at: https://globenewswire.com/newsrelease/2017/03/10/934363/0/en/21-12-Billion-Implantable-Biomaterials-Market-Global-Forecasts-to-2023-

Miniaturization-of-Implant-Devices-and-Increasing-Minimally-Invasive-Surgery.html. [accessed April 1, 2017].

[7] Pruitt, L., Furmanski, J. (n.d.). Polymeric biomaterials for load-bearing medical devices, JOM, 61(9), pp. 14-20. DOI: $10.1007 / \mathrm{s} 11837-009-0126-3$.

[8] Evans, S.L., Gregson, P.J. (1998). Composite technology in load-bearing orthopaedic implants., Biomaterials, 19(15), pp. 1329-1342.

[9] Nagels, J., Stokdijk, M., Rozing, P.M. (n.d.). Stress shielding and bone resorption in shoulder arthroplasty.

[10] Huiskes, R., Weinans, H., van Rietbergen, B. (1992). The relationship between stress shielding and bone resorption around total hip stems and the effects of flexible materials., Clin. Orthop. Relat. Res., 274, pp. 124-134.

[11] Peron, M., Torgersen, J., Berto, F. (2017). Mg and Its Alloys for Biomedical Applications: Exploring Corrosion and Its Interplay with Mechanical Failure, Metals (Basel)., 7(7), pp. 252. DOI: 10.3390/met7070252.

[12] Niinomi, M. (Mitsuo). (2010). Metals for biomedical devices, CRC Press.

[13] Black, J. (2006). Biological performance of materials : fundamentals of biocompatibility, CRC Taylor \& Francis.

[14] Ramakrishna, S., Mayer, J., Wintermantel, E., Leong, K.W. (n.d.). Biomedical applications of polymer-composite materials: a review.

[15] Fraldi, M., Esposito, L., Perrella, G., Cutolo, A., Cowin, S.C., Esposito, L. (2010). Topological optimization in hip prosthesis design, Biomech Model Mechanobiol, 9, pp. 389-402. DOI: 10.1007/s10237-009-0183-0.

[16] Peron, M., Torgersen, J., Ferro, P., Berto, F. (2018). Fracture behaviour of notched as-built EBM parts: Characterization and interplay between defects and notch strengthening behaviour, Theor. Appl. Fract. Mech., 98, pp. 178-85. DOI: 10.1016/J.TAFMEC.2018.10.004.

[17] E Murr, L., M Gaytan, S., Martinez, E., Medina, F.R., Wicker, R.B. (2012). Fabricating Functional Ti-Alloy Biomedical Implants by Additive Manufacturing Using Electron Beam Melting, J. Biotechnol. Biomater., 02(03). DOI: $10.4172 / 2155-952 X .1000131$.

[18] Obaton, A.-F., Fain, J., Djemaï, M., Meinel, D., Léonard, F., Mahé, E., Lécuelle, B., Fouchet, J.-J., Bruno, G. (2017). In vivo XCT bone characterization of lattice structured implants fabricated by additive manufacturing, Heliyon, 3(8). DOI: 10.1016/J.HELIYON.2017.E00374.

[19] Smeets, R., Stadlinger, B., Schwarz, F., Beck-Broichsitter, B., Jung, O., Precht, C., Kloss, F., Gröbe, A., Heiland, M., Ebker, T., Ebker, T. (2016). Impact of Dental Implant Surface Modifications on Osseointegration, Biomed Res. Int., 2016, pp. 1-16. DOI: $10.1155 / 2016 / 6285620$.

[20] Albrektsson, T., Wennerberg, A. (n.d.). Oral implant surfaces: Part 1--review focusing on topographic and chemical properties of different surfaces and in vivo responses to them., Int. J. Prosthodont., 17(5), pp. 536-43.

[21] Osman, R., Swain, M. (2015). A Critical Review of Dental Implant Materials with an Emphasis on Titanium versus Zirconia, Materials (Basel)., 8(3), pp. 932-58. DOI: 10.3390/ma8030932.

[22] Gil, F.J., Herrero-Climent, M., Lázaro, P., Rios, J. V. (2014). Implant-abutment connections: influence of the design on the microgap and their fatigue and fracture behavior of dental implants, J. Mater. Sci. Mater. Med., 25(7), pp. 
1825-30. DOI: 10.1007/s10856-014-5211-7.

[23] Sivakumar, M., Rajeswari, S. (1992). Investigation of failures in stainless steel orthopaedic implant devices: pit-induced stress corrosion cracking, J. Mater. Sci. Lett., 11(15), pp. 1039-42. DOI: 10.1007/BF00729754.

[24] Yokoyama, K., Ichikawa, T., Murakami, H., Miyamoto, Y., Asaoka, K. (2002). Fracture mechanisms of retrieved titanium screw thread in dental implant, Biomaterials, 23(12), pp. 2459-65. DOI: 10.1016/S0142-9612(01)00380-5.

[25] Chao, J., López, V. (2007). Failure analysis of a Ti6Al4V cementless HIP prosthesis, Eng. Fail. Anal., 14(5), pp. 82230. DOI: 10.1016/J.ENGFAILANAL.2006.11.003.

[26] Prawoto, Y. (n.d.). Integration of mechanics into materials science research: a guide for material researchers in analytical, computational and experimental methods, .

[27] Verreman, Y., Nie, B. (1996). Early development of fatigue cracking at manual fillet welds, Fatigue Fract. Eng. Mater. Struct., 19(6), pp. 669-681. DOI: 10.1111/j.1460-2695.1996.tb01312.x.

[28] Lazzarin, P., Tovo, R. (1998). A notch intensity factor approach to the stress analysis of welds, Fatigue Fract. Eng. Mater. Struct., 21(9), pp. 1089-1103. DOI: 10.1046/j.1460-2695.1998.00097.x.

[29] Williams, M.L. (1952). Stress singularities resulting from various boundary conditions in angular corners on plates in extension, J. Appl. Mech., 19, pp. 526-528.

[30] Kasiri, S., Taylor, D. (2008). A critical distance study of stress concentrations in bone, J. Biomech., 41(3), pp. 603-9. DOI: 10.1016/J.JBIOMECH.2007.10.003.

[31] Taylor, D. (1999). Geometrical effects in fatigue: a unifying theoretical model, Int. J. Fatigue, 21(5), pp. 413-420. DOI: $10.1016 /$ S0142-1123(99)00007-9.

[32] Razavi, S.M.J., Peron, M., Torgersen, J., Berto, F., Mutignani, F. (2017). Effect of hot dip galvanization on the fatigue strength of steel bolted connections, Frat. Ed Integrita Strutt., 11(41). DOI: 10.3221/IGF-ESIS.41.54.

[33] Razavi, S.M.J., Peron, M., Torgersen, J., Berto, F. (2017). Static Multiaxial Fracture Behavior of Graphite Components: A Review of Recent Results, Key Eng. Mater., 754, pp. 35-38. DOI: 10.4028/www.scientific.net/KEM.754.35.

[34] Razavi, S.M.J., Peron, M., Mutignani, F., Torgersen, J., Berto, F. (2017). A Study on the Fatigue Behavior of Hot Dip Galvanized Steel Connections, Key Eng. Mater., 754, pp. 241-243. DOI: 10.4028/www.scientific.net/KEM.754.241.

[35] Berto, F., Lazzarin, P. (2009). A review of the volume-based strain energy density approach applied to V-notches and welded structures, Theor. Appl. Fract. Mech., 52(3), pp. 183-194. DOI: 10.1016/j.tafmec.2009.10.001.

[36] Peron, M., Razavi, S.M.J., Berto, F., Torgersen, J., Colussi, M. (2017). Fracture assessment of magnetostrictive materials, Frat. Ed Integrita Strutt., 11(42). DOI: 10.3221/IGF-ESIS.42.24.

[37] Campagnolo, A., Razavi, S.M.J., Peron, M., Torgersen, J., Berto, F. (2017). Mode II brittle fracture: Recent developments, Frat. Ed Integrita Strutt., 11(42). DOI: 10.3221/IGF-ESIS.42.19.

[38] Razavi, S.M.J., Peron, M., Torgersen, J., Berto, F. (2017). Notched graphite under multiaxial loading, Frat. Ed Integrita Strutt., 11(41). DOI: 10.3221/IGF-ESIS.41.53.

[39] Peron, M., Razavi, S.M.J., Berto, F., Torgersen, J. (2017). Notch stress intensity factor under mixed mode loadings: an overview of recent advanced methods for rapid calculation, Frat. Ed Integrità Strutt., 42, pp. 196-204.

[40] Peron, M., Razavi, S.M.J., Berto, F., Torgersen, J., Mutignani, F. (2017). Local strain energy density for the fatigue assessment of hot dip galvanized welded joints: Some recent outcomes, Frat. Ed Integrita Strutt., 11(42). DOI: $10.3221 /$ IGF-ESIS.42.22.

[41] Razavi, S.M.J., Peron, M., Mutignani, F., Torgersen, J., Berto, F. (2017). Fatigue Strength of Hot-Dip Galvanized Welded Steel Connections, Key Eng. Mater., 754, pp. 244-7. DOI: 10.4028/www.scientific.net/KEM.754.244.

[42] Chebat, F., Peron, M., Viespoli, L., Welo, T., Berto, F. (2018). Fatigue Strength Assessment of Steel Rollers: On the Reliability of the Strain Energy Density Approach on Real Components, Appl. Sci., 8(7), pp. 1015. DOI: $10.3390 /$ app8071015.

[43] Peron, M., Torgersen, J., Berto, F. (2018). Rupture Predictions of Notched Ti-6Al-4V Using Local Approaches, Materials (Basel)., 11(5), pp. 663. DOI: 10.3390/ma11050663.

[44] (2012). Fracture behaviour of notched round bars made of PMMA subjected to torsion at room temperature, Eng. Fract. Mech., 90, pp. 143-160. DOI: 10.1016/J.ENGFRACMECH.2012.05.001.

[45] Berto, F., Cendon, D.A., Lazzarin, P., Elices, M. (2013). Fracture behaviour of notched round bars made of PMMA subjected to torsion at $60^{\circ} \mathrm{C}$. DOI: $10.1016 /$ j.engfracmech.2013.02.011.

[46] Peron, M., Razavi, S.M.J., Berto, F., Torgersen, J., Marsavina, L. (2017). Local strain energy density for the fracture assessment of polyurethane specimens weakened by notches of different shape, 4232214223(10), pp. 214-22. DOI: $10.3221 /$ IGF-ESIS.42.23.

[47] Peron, M., Razavi, S., Torgersen, J., Berto, F. (2017). Fracture Assessment of PEEK under Static Loading by Means 
of the Local Strain Energy Density, Mater. 2017, Vol. 10, Page 1423, 10(12), pp. 1423. DOI: 10.3390/MA10121423.

[48] Peron, M., Torgersen, J., Berto, F., Peron, M., Torgersen, J., Berto, F. (2018). A Novel Approach for Assessing the Fatigue Behavior of PEEK in a Physiologically Relevant Environment, Mater. 11, pp. 1923. DOI: $10.3390 /$ MA11101923.

[49] Ulery, B.D., Nair, L.S., Laurencin, C.T. (2011). Biomedical Applications of Biodegradable Polymers., J. Polym. Sci. B. Polym. Phys., 49(12), pp. 832-864. DOI: 10.1002/polb.22259.

[50] Maitz, M.F. (2015). Applications of synthetic polymers in clinical medicine, Biosurface and Biotribology, 1, pp. 161176. DOI: $10.1016 /$ j.bsbt.2015.08.002.

[51] Williams, D.F. (2009). On the nature of biomaterials, Biomaterials, 30(30), pp. 5897-5909. DOI: 10.1016/j.biomaterials.2009.07.027.

[52] Lendlein, A., Rehahn, M., Buchmeiser, M.R., Haag, R. (2010). Polymers in Biomedicine and Electronics, Macromol. Rapid Commun., 31(17), pp. 1487-1491. DOI: 10.1002/marc.201000426.

[53] Williams, D.F., McNamara, A., Turner, R.M. (1987). Potential of polyetheretherketone (PEEK) and carbon-fibrereinforced PEEK in medical applications, J. Mater. Sci. Lett., 6(2), pp. 188-190. DOI: 10.1007/BF01728981.

[54] Platt, D.K., Rapra Technology Limited. (2003). Engineering and high performance plastics market report: a Rapra market report, Rapra Technology Ltd.

[55] Walter, J., Kuhn, S.A., Reichart, R., Kalff, R., Ewald, C. (2010). PEEK cages as a potential alternative in the treatment of cervical spondylodiscitis: a preliminary report on a patient series., Eur. Spine J., 19(6), pp. 1004-1009. DOI: $10.1007 / \mathrm{s} 00586-009-1265-5$.

[56] Schwitalla, A., Müller, W.-D. (2013). PEEK Dental Implants: A Review of the Literature, J. Oral Implantol., 39(6), pp. 743-749. DOI: 10.1563/AAID-JOI-D-11-00002.

[57] Rahmitasari, F., Ishida, Y., Kurahashi, K., Matsuda, T., Watanabe, M., Ichikawa, T. (2017). PEEK with Reinforced Materials and Modifications for Dental Implant Applications., Dent. J., 5(4). DOI: 10.3390/dj5040035.

[58] Sagomonyants, K.B., Jarman-Smith, M.L., Devine, J.N., Aronow, M.S., Gronowicz, G.A. (2008). The in vitro response of human osteoblasts to polyetheretherketone (PEEK) substrates compared to commercially pure titanium, Biomaterials, 29(11), pp. 1563-1572. DOI: 10.1016/j.biomaterials.2007.12.001.

[59] Lee, W.-T., Koak, J.-Y., Lim, Y.-J., Kim, S.-K., Kwon, H.-B., Kim, M.-J. (2012). Stress shielding and fatigue limits of poly-ether-ether-ketone dental implants, J. Biomed. Mater. Res. Part B Appl. Biomater., 100B(4), pp. 1044-1052. DOI: $10.1002 /$ jbm.b.32669.

[60] Sobieraj, M.C., Kurtz, S.M., Rimnac, C.M. (2009). Notch sensitivity of PEEK in monotonic tension., Biomaterials, 30(33), pp. 6485-6494. DOI: 10.1016/j.biomaterials.2009.08.020.

[61] Sobieraj, M.C., Murphy, J.E., Brinkman, J.G., Kurtz, S.M., Rimnac, C.M. (2010). Notched fatigue behavior of PEEK, Biomaterials, 31(35), pp. 9156-9162. DOI: 10.1016/j.biomaterials.2010.08.032.

[62] Dowling, N.E. (2007). Mechanical behavior of materials : engineering methods for deformation, fracture and fatigue, Upper Saddle River, NJ, Pearson Prentice Hall.

[63] Lazzarin, P., Zambardi, R. (2001). A finite-volume-energy based approach to predict the static and fatigue behavior of components with sharp V-shaped notches, Int. J. Fract., 112(3), pp. 275-298. DOI: 10.1023/A:1013595930617.

[64] Berto, F., Lazzarin, P. (2014). Recent developments in brittle and quasi-brittle failure assessment of engineering materials by means of local approaches, Mater. Sci. Eng. R, 75(1), pp. 1-48. DOI: 10.1016/j.mser.2013.11.001.

[65] Seweryn, A. (1994). Brittle fracture criterion for structures with sharp notches, Eng. Fract. Mech., 47(5), pp. 673-681. DOI: 10.1016/0013-7944(94)90158-9.

[66] Fuentes, J., Cicero, S., Berto, F., Torabi, A., Madrazo, V., Azizi, P. (2018). Estimation of Fracture Loads in AL7075T651 Notched Specimens Using the Equivalent Material Concept Combined with the Strain Energy Density Criterion and with the Theory of Critical Distances, Metals (Basel) 8(2), pp. 87. DOI: 10.3390/met8020087.

[67] Beltrami, E., E. (1885). Sulle condizioni di resistenza dei corpi elastici, Nuovo Cim., 18(1), pp. 145-155. DOI: $10.1007 / \mathrm{BF} 02824697$.

[68] Berto, F., Gallo, P., Razavi, S.M.J., Ayatollahi, M.R. (2017). Fatigue behavior of innovative alloys at elevated temperature, Procedia Struct. Integr., 3, pp. 162-167. DOI: 10.1016/j.prostr.2017.04.029.

[69] Albérola, N.D., Mélé, P., Bas, C. (1997). Tensile mechanical properties of PEEK films over a wide range of strain rates. II, J. Appl. Polym. Sci., 64(6), pp. 1053-1059.

DOI: 10.1002/(SICI)1097-4628(19970509)64:6<1053::AID-APP3>3.0.CO;2-K. 